Page I - 18

\title{
Pengaruh Gaya Kepemimpinan terhadap Komitmen Organisasi Melalui Kepuasan Kerja Sebagai Variabel Intervening
}

\author{
Arif Darmawan', Marlinda Aulia Putri² \\ Accounting Department, Batam State of Polytechnic \\ 'arif.darmawan4@gmail.com, ²marlindaauliaputri2103@gmail.com
}

\begin{abstract}
This study aims to examine the influence of leadership style on organizational commitment through job satisfaction as intervening variable. This research uses quantitative method with data analysis that is simple regression, path analysis and test of sobel. he results showed that leadership style influence job satisfaction, while job satisfaction affect organizational commitment. The result of path analysis showed that leadership style influence to organizational commitment through job satisfaction as intervening variable. The implications obtained in this study are expected to be used as information for universities to apply good leadership style and pay more attention to job satisfaction from lecturers.
\end{abstract}

Key Words: leadership style, job satisfaction, organizational commitment

\begin{abstract}
Abstrak
Penelitian ini bertujuan untuk menguji pengaruh gaya kepemimpinan terhadap komitmen organisasi melalui kepuasan kerja sebagai variabel intervening. Penelitian ini menggunakan metode kuantitatif dengan analisis data yaitu regresi sederhana, analisis jalur dan uji sobel test. Hasil penelitian menunjukkan bahwa gaya kepemimpinan mempengaruhi kepuasan kerja, sedangkan kepuasan kerja mempengaruhi komitmen organisasi. Hasil uji analisis jalur menunjukkan hasil bahwa gaya kepemimpinan berpengaruh terhadap komitmen organisasi melalui kepuasan kerja sebagai variabel intervening. Implikasi yang didapatkan dalam penelitian ini diharapkan dapat digunakan sebagai informasi bagi pihak perguruan tinggi untuk dapat menerapkan gaya kepemimpinan yang baik dan lebih memperhatikan kepuasan kerja dari dosen.
\end{abstract}

Kata Kunci: gaya kepemimpinan, kepuasan kerja, komitmen organisasi

Diterima: 4 Januari 2017; Revisi: I5 Februari 20I7; Disetujui: 5 Maret 2017 


\section{PENDAHULUAN}

Suatu organisasi atau perusahaan diperlukan seorang pemimpin yang mampu membawa perusahaan mempertahankan konsistensi dan bersaing di dunia bisnis. Begitu penting peran kepemimpinan dalam perusahaan atau organisasi dalam pencapaian suatu misi, visi dan tujuan.Tidak adanya seorang pemimpin dapat menjadikan suatu perusahaan atau organisasi mengalami kemunduran. Bass (1990) yang menyatakan bahwa kualitas dari pemimpin sering dianggap sebagai faktor terpenting yang menentukan keberhasilan atau kegagalan organisasi. Organisasi membutuhkan kepemimpinan yang kuat agar efektivitasnya optimal (Robbins, 2008).

Penelitian mengenai kepemimpinan lebih menekankan kepada gaya (Robbins, 2008). Penerapan gaya kepemimpinan dapat memberikan pengaruh kepada bawahan terutama terhadap kepuasan kerja karyawan. Mengingat akan pentingnya gaya kepemimpinan yang diterapkan seorang pemimpin, maka diharapkan seorang pemimpin dapat memberikan sesuatu yang positif dalam meningkatkan kepuasan kerja karyawan. Studi Long et al. (2013) memberikan hasil adanya hubungan yang kuat dan signifikan positif antara gaya kepemimpinan dengan kepuasan kerja.

Kepuasan kerja memainkan peran yang penting dalam menuju keberhasilan organisasi. Menurut Robbins (2008), aspek-aspek kepuasan kerja termasuk upah, kondisi kerja, keamanan kerja, rekan kerja, jenis pekerjaan dan peluang karyawan untuk lebih maju. Perusahaan perlu memperhatikan aspek-aspek tersebut agar karyawan merasa kebutuhannya terpenuhi dan pada akhirnya mereka akan merasa terpuaskan.

Tingkat kepuasan kerja berkaitan dengan komitmen yang dimiliki karyawan terhadap organisasi. Hasil penelitian yang dilakukan oleh Malik et al. (2010) memberikan hasil bahwa kepuasan kerja mempunyai pengaruh yang signifikan dan positif terhadap komitmen organisasi. Hal ini berarti jika karyawan merasa puas maka akan menunjukkan hubungan yang positif dengan organisasi yang mengarah kepada komitmen. Karyawan yang merasa puas cenderung menjadi lebih setia dengan organisasi dan mempertahankan sikap positif terhadap pekerjaan, mereka tidak mungkin untuk berpindah pekerjaan dan menganggap pekerjaan mereka lebih baik dari yang lain. 
Penelitian ini merupakan pengembangan dari penelitian sebelumnya yang dilakukan oleh Long (20I3), dalam penelitiannya hanya meneliti gaya kepemimpinan transformasional dan kepuasan kerja. Penelitian ini menambah variabel komitmen organisasi untuk dikaitkan dengan gaya kepemimpinan dan kepuasan kerja. Dari beberapa uraian dan hasil studi yang dilakukan oleh beberapa peneliti, maka penulis tertarik untuk melakukan penelitian mengenai pengaruh gaya kepemimpinan terhadap komitmen organisasi melalui kepuasan kerja sebagai variabel intervening pada dosen manajemen bisnis dan ekonomi.

Sejauh ini banyak yang melakukan penelitian hanya pada perusahaan saja sedangkan untuk perguruan tinggi dirasa oleh peneliti juga perlu adanya perhatian. Dosen manajemen bisnis dan ekonomi dipilih sebagai sampel karena menurut peneliti yang lebih peduli dan lebih memperhatikan masalah kepemimpinan yaitu orang-orang bisnis.

Tujuan dari penelitian ini adalah mengkaji dan menguji pengaruh gaya kepemimpinan terhadap kepuasan kerja, mengkaji dan menguji pengaruh kepuasan kerja terhadap komitmen organisasi dan mengkaji dan menguji pengaruh gaya kepemimpinan terhadap komitmen organisasi melalui kepuasan kerja sebagai variabel intervening.

\section{KERANGKA TEORITIS DAN PENGEMBANGAN HIPOTESIS}

\section{Gaya Kepemimpinan}

Kepemimpinan memainkan peran utama dalam usaha memahami perilaku kelompok, karena pemimpinlah yang biasa memberikan pengarahan untuk mencapai tujuan (Robbins, 2008). Menurut Kartono (2003) kepemimpinan itu sendiri adalah suatu kegiatan mempengaruhi orang lain agar mau bekerjasama yang didasarkan pada kemampuan orang tersebut untuk membimbing orang lain dalam mencapai tujuantujuan yang diinginkan. Dengan kata lain, kepemimpinan merupakan kemampuan mempengaruhi orang lain untuk mencapai suatu tujuan.

Teori kepemimpinan itu sendiri ada tiga yaitu teori sifat kepemimpinan ini mempertimbangkan berbagai sifat dan karakteristik pribadi yang membedakan para pemimpin dari mereka yang bukan pemimpin. Teori perilaku kepemimpinan ini tidak menekankan pada sifat tetapi memfokuskan bagaimana cara pemimpin berperilaku dalam mempengaruhi orang lain. Teori jalan-tujuan 
merupakan teori yang mengemukakan bahwa tugas pemimpin untuk membantu para pengikut dalam mencapai tujuan-tujuan mereka dan untuk memberi pengarahan.

\section{Kepuasan Kerja}

Kepuasan kerja menurut Luthans (2006) yaitu hasil persepsi karyawan mengenai seberapa baik pekerjaan mereka memberikan hal yang dinilai penting. Kepuasan kerja adalah suatu sikap emosional yang menyenangkan dan mencintai pekerjaannya (Hasibuan, 2007). Menurut Robbins (2008) kepuasan kerja (job satisfaction) dapat didefinisikan sebagai suatu perasaan positif tentang pekerjaan seseorang yang merupakan hasil dari evaluasi karakteristiknya.

Teori perbedaan menyatakan bahwa seorang karyawan akan merasa puas bila tidak ada perbedaan antara apa yang diinginkan dengan kenyataannya. Teori dua faktor ini mengatakan bahwa kepuasan dan ketidakpuasan kerja itu merupakan dua hal yang berbeda. Berdasarkan penelitian yang dilakukannya, Herzberg membagi situasi yang mempengaruhi sikap seseorang terhadap pekerjaannya menjadi dua kelompok yaitu kelompok satisfiers dan dissatisfiers.

Komitmen Organisasi

Komitmen organisasi menurut Robbins (2003) adalah tingkat sampai mana seorang karyawan memihak sebuah organisasi serta tujuan-tujuan dan keinginannya untuk mempertahankan keanggotaannya dalam organisasi tersebut. Sama halnya dengan pendapat Rivai (2003) yang mengatakan bahwa komitmen organisasi adalah suatu keadaan seorang karyawan memihak pada suatu organisasi tertentu dan tujuantujuannya.

\section{Pengaruh Gaya Kepemimpinan terhadap Kepuasan Kerja}

Judge dan Locke (1993) menegaskan bahwa gaya kepemimpinan merupakan salah satu faktor penentu kepuasan kerja. Jika seorang pemimpin menerapkan gaya kepemimpinan yang mampu menciptakan suasana kondusif makadapat mendorong tingkat kepuasan kerja seorang karyawan, karyawan akan merasa menjadi lebih nyaman.

Penelitian Tondok dan Andarika (2004) menunjukkan bahwa ada hubungan yang signifikan dan berkorelasi positif antara gaya kepemimpinan berupa kepemimpinan transformasional dan transaksional dengan kepuasan kerja. Hasil yang sama juga 
didapatkan bahwa gaya kepemimpinan transformasional dan transaksional secara bersamaan berpengaruh signifikan terhadap kepuasan kerja karyawan (Setiawan, 20II).

Berdasarkan penjelasan yang telah diuraikan, maka hipotesis yang dapat dirumuskan adalah sebagai berikut:

HI: Gaya kepemimpinan memiliki pengaruh terhadap kepuasan kerja.

Pengaruh Kepuasan Kerja terhadap Komitmen Organisasi

Kepuasan kerja mencerminkan tentang perasaan seseorang terhadap pekerjaanya, ketika seseorang puas terhadap pekerjaannya maka mereka akan lebih berkomitmen terhadap organisasi (Mathis dan Jackson, 20II). Hsiao dan Chen (20I2) dalam penelitiannya yang dilakukan pada beberapa perusahaan di Taiwan menyatakan bahwa kepuasan kerja memiliki pengaruh positif signifikan terhadap komitmen organisasional.

Beberapa penelitian terdahulu menyatakan bahwa kepuasan kerja berpengaruh terhadap komitmen organisasi. Penelitian sebelumnya juga menemukan hasil hubungan positif antara kepuasan kerja dan komitmen organisasi (Mohammed \& Eleswed, 20I3). Puspitawati dan Riana (2014), hasil penelitiannya menunjukkan bahwa kepuasan kerja berpengaruh positif terhadap komitmen organisasi. Hal ini menunjukkan bahwa karyawan yang merasa puas cenderung lebih setia kepada organisasi dan mempertahankan sikap positif terhadap pekerjaan mereka sehingga mereka tidak mungkin mengganti pekerjaan mereka.

H2: Kepuasan kerja memiliki pengaruh terhadap komitmen organisasi

Pengaruh Gaya Kepemimpinan terhadap Komitmen Organisasi Melalui Kepuasan Kerja sebagai Variabel Intervening

Gaya kepemimpinan secara tidak langsung mempengaruhi komitmen organisasi dengan peran mediasi yaitu kepuasan kerja. Kepuasan kerja dapat ditingkatkan melalui perhatian dan hubungan yang baik dari pimpinan kebawahan, sehingga karyawan akan merasa bahwa dirinya merupakan bagian yang penting dari organisasi. Kepuasan kerja menjadi aspek pertama yang dicapai sebelum seorang karyawan memiliki komitmen organisasi, dengan begitu karyawan yang memiliki 
kepuasan dalam bekerja maka akan menguatkan pengaruh kepemimpinan terhadap komitmen organisasi.

Penelitian yang dilakukan oleh Dewi (2013) memperoleh hasil bahwa kepuasan kerja mampu memediasi terhadap pengaruh gaya kepemimpinan dan komitmen oganisasi dengan dibuktikan nilai koefisien pengaruh tidak langsung yang lebih besar daripada langsung pada penelitiannya. Sejalan dengan hasil penelitian Mohamad (20I2) bahwa gaya kepemimpinan transformasional secara signifikan berkorelasi dengan kepuasan kerja dan komitmen organisasi dan juga kepuasan kerja memediasi hubungan antara dirasakan gaya kepemimpinan transformasional dan komitmen organisasi.

H3: Gaya kepemimpinan memiliki pengaruh terhadap komitmen organisasi melalui kepuasan kerja sebagai variabel intervening

Berikut ini adalah model penelitian yang dilakukan:

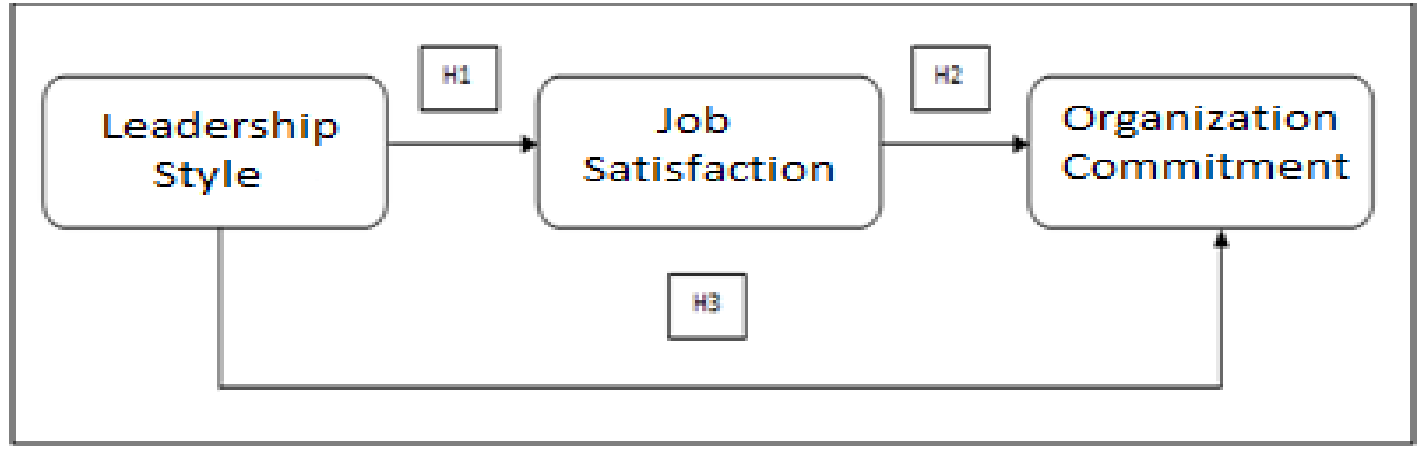

\section{Gambar I. Model Penelitian}

\section{METODE}

Desain Penelitian

Pendekatan dalam penelitian ini menggunakan pendekatan kuantitatif. Sumber data terdiri dari data primer. Alat yang dipergunakan dalam proses pengumpulan data berupa kuesioner. Metode skala untuk instrumen menggunakan Skala Likert. Penelitian ini dilakukan pada kampus di Batam yaitu: Politeknik Negeri Batam, Universitas Batam, Universitas Internasional Batam, Universitas Riau Kepulauan, Universitas Putera Batam, Sekolah Tinggi Ilmu Ekonomi lbnu Sina. 
Obyek penelitian itu sendiri yaitu tenaga pendidik dalam hal ini dosen manajemen bisnis dan fakultas ekonomi. Populasi berjumlah 2/4 dosen, sedangkan untuk sampel berjumlah 144 responden. Teknik penetapan sampel menggunakan slovin. Teknik penarikan sampel menggunakan purposive sampling. Teknik purposive sampling merupakan teknik pengambilan sampel berdasarkan dengan pertimbangan tertentu (Sugiyono, 2006).

Instrumen Penelitian

Kuesioner didistribusikan terdiri dari tiga bagian:

a) Profil Demografis.

Data demografi dikumpulkan dengan lima item, yang meliputi perguruan tinggi, jenis kelamin, usia, tingkat pendidikan dan lama bekerja.

b) Pengukuran Gaya Kepemimpinan.

Gaya Kepemimpinan berupa kepemimpinan transformasional yang terdiri dari Idealized Influence, Inspirational Motivation, Intellectual Stimulation, Individualized Consideration dan kepemimpinan transaksional yang terdiri dari Contingent Reward, Management by Exception-Active, Management by Exception-Passive. The Multifactor Leadership Questionnaire (MLQ) (Bernard Bass and Bruce Avolio, 1994) digunakan untuk mengukur gaya kepemimpinan transformasional dan transaksional.

c) Pengukuran Kepuasan Kerja.

Kepuasan Kerja berupa Pay (gaji), Promotion (promosi), Supervisor (atasan), Co-worker (rekan kerja), Fringe benefits (tunjangan), Contigent rewards (imbalan non-finansial), Operating procedures (kondisi operasional), Nature of work (jenis pekerjaan), dan Communication (komunikasi). Job Satisfaction Survey (JSS) (Spector, 1997) digunakan untuk mengukur kepuasan kerja.

d) Pengukuran Komitmen Organisasi

Komitmen organisasional berupa komitmen afektif (affective commitment), komitmen kelanjutan (continuance commit-ment), dan komitmen normatif (normative commitment). Three Component Organizational Commitment Questionnaire (Allen \& Meyer, 1990) digunakan untuk mengukur variabel komitmen organisasi. 


\section{HASIL DAN PEMBAHASAN}

\section{Karakteristik Responden}

\begin{tabular}{|c|c|c|c|}
\hline \multicolumn{4}{|c|}{$\begin{array}{c}\text { Tabel I } \\
\text { Karakteristik Responden }\end{array}$} \\
\hline Information & & Total & Percentage(\%) \\
\hline \multirow[t]{3}{*}{ University } & High School & 19 & 13,2 \\
\hline & University & 99 & 68,8 \\
\hline & Polytechnic & 26 & $18, \mid$ \\
\hline \multirow[t]{2}{*}{ Gender } & Man & 68 & 47,2 \\
\hline & Woman & 76 & 52,8 \\
\hline \multirow[t]{3}{*}{ Education } & Bachelor & 43 & 29,9 \\
\hline & Master & 87 & 60,4 \\
\hline & Professor & 14 & 9,7 \\
\hline \multirow[t]{4}{*}{ Age } & $<25$ years old & 40 & 27,8 \\
\hline & $25-30$ years old & 98 & 68,1 \\
\hline & $30-35$ years old & 2 & $\mathrm{I}, 4$ \\
\hline & $>35$ years old & 4 & 2,8 \\
\hline Long & $<$ l years old & 33 & 22,9 \\
\hline \multirow[t]{3}{*}{ Working } & I-2 years old & 29 & 20,1 \\
\hline & 2-3 years old & 31 & 21,5 \\
\hline & $>3$ years old & 51 & 35,4 \\
\hline TOTAL & & 144 & 100 \\
\hline
\end{tabular}

Karakteristik umum responden meliputi perguruan tinggi, jenis kelamin, usia, tingkat pendidikan, dan lama bekerja dapat dilihat pada tabel I yang memperlihatkan bahwa persentase responden yang paling tinggi dalam penelitian ini adalah dosen pada perguruan tinggi yaitu sebesar $68,8 \%$. Responden perempuan dalam penelitian ini lebih mendominasi dibandingkan laki-laki dengan persentase sebesar $52,8 \%$. Usia responden paling banyak ada diantara 25-30 tahun dengan persentase sebesar 68, I\% dibandingkan dengan usia lainnya. Untuk waktu lama bekerja responden sebagai dosen paling banyak sudah melewati selama $>3$ tahun dilihat dari besarnya persentase yaitu 35,4\%. Hampir dari keseluruhan responden sudah menempuh pendidikan S2 dengan persentase $60,4 \%$.

\section{Validitas dan Reliabilitas}

Pengujian validitas menggunakan Korelasi Pearson dan pengujian reliabilitas menggunakan Cronbach Alpha. Uji validitas dilakukan dengan membandingkan nilai $r$ hitung dengan $r$ tabel. Jika $r$ hitung $>r$ tabel dan nilai positif maka butir pertanyaan atau indikator tersebut dinyatakan valid. Suatu konstruk atau variabel dikatakan reliabel jika 
memberikan nilai Cronbach Alpha (a) > 0,70 (Ghozali, 20II). Berikut adalah hasil uji validitas dan reliabilitas:

Tabel 2

Validity and Reliability

\begin{tabular}{lll}
\hline Variable & Pearson Correlation & $\begin{array}{l}\text { Cronbach } \\
\text { Alpha }\end{array}$ \\
\hline Leadership Style $(\mathrm{X})$ & $0,512-0,779 * *$ & $0,7 \mid 3$ \\
Job Satisfaction $(\mathrm{M})$ & $0,477-0,783^{* *}$ & 0,844 \\
Organization Commitment $(\mathrm{Y})$ & $0,736-0,879 *$ & 0,842 \\
\hline
\end{tabular}

** Significant pada level 0,0I

\section{Hasil Uji Asumsi Klasik}

\section{Hasil Uji Normalitas}

Uji normalitas bertujuan untuk menguji apakah dalam model regresi, variabel terikat dan variabel bebas keduanya memiliki distribusi normal atau tidak (Ghozali, 20II). Pengujian nomalitas dapat dilihat melalui uji Kolmogorov-Smirnov (K-S). Apabila nilai sig $>$ 0,05 maka data terdistribusi secara normal. Berdasarkan uji KS diperoleh nilai sig 0,200 lebih besar dari 0,05. Sehingga dapat disimpulkan bahwa data berdistribusi normal.

Tabel 3

Normality Test

\begin{tabular}{ll}
\hline & Precentage \\
\hline Kolmogorov Smirnov Z & 0,058 \\
Assymp. Sig. (2-tailed) & 0,200 \\
\hline
\end{tabular}

Source: Data Processed

\section{Hasil Uji Multikolonieritas}

Uji multikolenieritas digunakan untuk menguji apakah dalam model regresi ditemukan adanya korelasi antar variabel bebas atau independen (Ghozali, 20II). Model regresi yang baik seharusnya tidak terjadi korelasi antara variabel independennya. Jika nilai VIF lebih kecil dari 10 dan tolerance lebih besar dari 0, 10 maka tidak terjadi multikolonieritas. Berdasarkan Tabel 4, dapat dilihat bahwa data tidak terjadi multikolinearitas dengan nilai tolerance lebih besar dari 0,10 dan nilai VIF masing-masing variabel lebih kecil dari 10. 
Tabel 4

Hasil Uji Multikolinearitas

\begin{tabular}{lcc}
\hline \multirow{2}{*}{ Model } & \multicolumn{2}{c}{ Collinearity Statistics } \\
\cline { 2 - 3 } & Tolerance & VIF \\
\hline Leadership Style & 0,727 & 1,376 \\
Job Satisfaction & 0,727 & 1,376
\end{tabular}

Source: Data Processed

\section{Hasil Uji Heteroskedastisitas}

Ghozali (20II) uji heteroskedastisitas bertujuan untuk menguji apakah dalam model regresi terjadi ketidaksamaan variance dari residu suatu pengamatan ke pengamatan lain. Model regresi yang baik adalah yang Homoskesdasitas atau tidak terjadi Heteroskesdatisitas. Pengujian heteroskedastisitas dapat dilakukan menggunakan pengujian secara statistik, yaitu dengan menggunakan metode Glejser Test. Jika nilai sig $>0.05$, maka tidak terjadi heteroskedastisitas. Berdasarkan Tabel 5, dapat dilihat bahwa nilai sig dari leadership style adalah 0,819 sehingga dapat disimpulkan data terbebas dari masalah heterokedastisitas.

Tabel 5

\section{Hasil Uji Heteroskedastisitas}

\begin{tabular}{ll}
\hline Model & Sig. \\
\hline Leadership Style & 0,819 \\
\hline
\end{tabular}

Source: Data Processed

\section{Hasil Uji Hipotesis}

Pengujian hipotesis dilakukan untuk mendeteksi pengaruh variabel intervening dalam memediasi variable independen terhadap variable dependen digunakan metode Analisis Regresi, Analisis Jalur dan Sobel Test.

\section{Regression Analysis}

Analisis regresi linier digunakan untuk mengetahui arah hubungan antara variabel independen dengan variabel intervening, dan variabel intervening dengan variabel dependen.

Tabel 6

\section{Regression Analysis Result H I}

\begin{tabular}{llll}
\hline & Coefficients & T & Sig. \\
\hline Constant & 30,845 & 8,286 & 0,000 \\
Leadership Style & 1,122 & 7,583 & 0,000 \\
\hline Source: Data Processed & &
\end{tabular}


Berdasarkan hasil dari Tabel 6, diperoleh persamaan regresi sebagai berikut: $\mathrm{KK}=30,845+\mathrm{I}, \mathrm{I} 22 \mathrm{GK}+\mathrm{e}$

Dari hasil output uji t yang pertama dapat dilihat bahwa untuk variabel gaya kepemimpinan diperoleh t hitung sebesar 7,583 dengan nilai signifikansi 0,000<0,05 sehingga dapat disimpulkan bahwa $\mathrm{HI}$ terdukung.

Berdasarkan hasil analisis regresi pengujian $H_{1}$ yang disajikan pada tabel 2 menyatakan bahwa untuk nilai koefisien standardized beta sebesar 0,148 yang merupakan nilai path. Untuk variabel gaya pemimpinan diperoleh $t$ hitung sebesar 7,583 dengan nilai siginifikansi sebesar 0,000 ini berarti signifikansi dapat disimpulkan bahwa $\boldsymbol{H I}$ terdukung.

Dapat dikatakan bahwa terdapat pengaruh antara gaya kepemimpinan dengan kepuasan kerja. Kepuasan kerja itu sendiri terpengaruh dengan gaya kepemimpinan, karena ketika dosen merasa bahwa ketika gaya kepemimpinan didalam sebuah perguruan tinggi mampu menciptakan suasana yang kondusif yaitu suasana yang memberikan suatu ketenangan dan dukungan maka dapat mendorong tingkat kepuasan kerja seorang dosen, dosen akan merasa menjadi lebih nyaman dalam organisasi. Hubungan yang akrab dengan pemimpin juga sangat penting dan memiliki hubungan kuat dengan kepuasan kerja, semakin baik pemimpin dalam membawahi bawahannya maka semakin nyaman dan puas juga para bawahan dalam melakukan pekerjaanya, begitu pula sebaliknya. Hasil penelitian ini mendukung penelitian Tondok dan Andarika (2004) yang menunjukkan hasil bahwa ada hubungan yang signifikan dan berkorelasi positif antara gaya kepemimpinan dengan kepuasan kerja. Selain itu penelitian ini juga mendapatkan dukungan dari penelitian yang dilakukan oleh Long, et al (2013) serta penelitian yang dilakukan oleh (Azri dan Farahbod, 2014) di Iran.

\section{Tabel 7}

\section{Regression Analysis Result H2}

\begin{tabular}{llll}
\hline & Coefficients & T & Sig. \\
\hline Constant & 5,367 & 2,553 & 0,012 \\
Leadership Style & 0.082 & 1,006 & 0,316 \\
Job Satisfaction & 0,137 & 3,529 & 0,001 \\
\hline
\end{tabular}

Source: Data Processed 
Berdasarkan hasil dari tabel di atas, diperoleh persamaan regresi sebagai berikut: $\mathrm{KO}=5,367+0,082 \mathrm{GK}+0,137 \mathrm{KK}+\mathrm{e}$

Dari hasil uji $t$ yang kedua dapat dilihat bahwa untuk gaya kepemimpinan diperoleh $\mathrm{t}$ hitung sebesar 1,006 dengan nilai sig 0,316 $<0.05$ sehingga dapat disimpulkan bahwa gaya kepeimpinan berpengaruh terhadap komitmen organisasi. Sedangkan untuk variabel kepuasan kerja diperoleh $\mathrm{t}$ hitung 3,529 dengan nilai sig 0,00I $<0,05$ sehingga dapat disimpulkan bahwa $\boldsymbol{H 2}$ terdukung.

Dapat dikatakan bahwa terdapat pengaruh antara kepuasan kerja terhadap komitmen organisasi. Hal ini berarti komitmen organisasi dapat ditingkatkan apabila kepuasan kerja seorang dosen terpenuhi dengan baik. Dosen akan memiliki kemauan yang tinggi untuk melaksanakan tanggung jawabnya, memiliki kesetiaan dan kebanggaan terhadap organisasi tempat mereka bekerja sebagai timbal balik atas apa yang mereka terima. Adanya dosen yang merasa puas juga akan mempertahankan sikap positif terhadap pekerjaan mereka sehingga mereka tidak mungkin mengganti pekerjaan mereka. Hasil penelitian ini sejalan dengan penelitian sebelumnya yang juga menemukan hasil bahwa kepuasan kerja berpengaruh positif terhadap komitmen organisasi (Puspitawati \& Riana, 2014).

\section{Analisis Jalur (Path Analysis)}

Analisis jalur digunakan untuk menguji pengaruh variabel intervening. Koefisien jalur hitung dengan membuat persamaan struktural yaitu persamaan regresi yang menunjukkan hubungan yang dihipotesiskan.

(I) $\mathrm{KK}=30,845+\mathrm{I}, \mathrm{I} 22 \mathrm{GK}+\mathrm{e}$

(2) $\mathrm{KO}=5,367+0,082 \mathrm{GK}+0,137 \mathrm{KK}+\mathrm{e}$

Pengaruh variabel independen terhadap variabel dependen melalui variabel intervening dengan menggunakan analisis jalur sebagai berikut:

\section{Tabel 8}

Nilai Pengaruh Berdasarkan Analisis Jalur

\begin{tabular}{lllll}
\hline Keterangan & $\begin{array}{l}\text { Pengaruh } \\
\text { Langsung }\end{array}$ & $\begin{array}{l}\text { Pengaruh } \\
\text { Langsung }\end{array}$ & Tidak & Total Pengaruh \\
\hline $\mathrm{XI} \rightarrow \mathrm{Y}$ & $\mathrm{pl}=0,082$ & $\mathrm{p} 2 \times \mathrm{p} 3=0,1537$ & 0,2357 \\
\hline
\end{tabular}

Sumber: Olah Data 


\section{Perhitungan Sobel (Sobel Test)}

Perhitungan sobel digunakan untuk menguji apakah pengaruh mediasi tidak langsung dari hasil perkalian koefisien ( 2 2 $\times 1$ p3) signifikan atau tidak. Berikut perhitungan mediasi berdasarkan nilai pengaruh dari analisis jalur:

$$
\begin{aligned}
\text { Sab } & =\sqrt{b^{2} S a^{2}+a^{2} S b^{2}+S a^{2} S b^{2}} \\
& =\sqrt{(0,137)^{2}(0,148)^{2}+(1,122)^{2}(0,039)^{2}+(0,148)^{2}(0,325)^{2}} \\
& =\sqrt{0,000411+0,001915+0,0002314} \\
& =0,0025574
\end{aligned}
$$

Berdasarkan hasil perhitungan di atas, nilai t hitung untuk menguji pengaruh variabel intervening dengan rumus sebagai berikut:

$$
\mathrm{t}=\frac{a b}{S a b}=\frac{0,148 \times 0,137}{0,0025574}=\frac{0,020276}{0,0025574}=7,92836474544
$$

Oleh karena $\mathrm{t}$ hitung $=7,928$ lebih besar dari $\mathrm{t}$ tabel dengan tingkat sig 0,05 yaitu sebesar 1,655, maka dapat disimpulkan bahwa koefisien mediasi 0.1537signifikan dan berarti terdapat pengaruh mediasi. Dengan adanya pengaruh mediasi maka dapat disimpulkan bahwa $\boldsymbol{H} \mathbf{3}$ terdukung.

Dapat dikatakan bahwa terdapat pengaruh antara gaya kepemimpinan terhadap komitmen organisasi melalui kepuasan kerja sebagai variabel intervening. Hal ini menunjukkan bahwa ketika gaya kepemimpinan mampu menciptakan suasana yang baik dan efektif maka dosen akan merasa puas dalam pekerjaannya dan akan timbul perasaan senang dengan pemimpin. Munculnya rasa kepuasaan kerja akan berdampak pada komitmen organisasi, dosen akan menjadi setia dengan pekerjaannya dan tidak ingin pindah dari pekerjaannya tersebut. Adanya komitmen yang tinggi akan memiliki rasa sungguh-sungguh dalam pekerjaan dan perasaan positif terhadap organisasi. Hasil penelitian ini mendukung penelitian sebelumnya Mohamad (2012) bahwa gaya kepemimpinan transformasional secara signifikan berkorelasi dengan kepuasan kerja dan komitmen organisasi dan juga kepuasan kerja memediasi hubungan antara dirasakan gaya kepemimpinan transformasional dan komitmen organisasi. 


\section{SIMPULAN}

Kesimpulan dari hasil pengujian yaitu berdasarkan hasil regresi dan uji sobel didapatkan bahwa gaya kepemimpinan berpengaruh terhadap kepuasan kerja karyawan. Gaya kepemimpinan menjadi faktor penting yang mempengaruhi perilaku kerja seperti kepuasan. Kepuasan kerja berpengaruh terhadap komitmen organisasi. Dengan adanya dosen yang merasa puas maka akan cenderung lebih setia kepada organisasi. Gaya kepemimpinan berpengaruh terhadap komitmen organisasi melalui kepuasan kerja sebagai variabel intervening. Ketika gaya kepemimpinan mampu menciptakan suasana yang baik dan efektif maka dosen akan merasa puas dalam pekerjaannya sehingga akan berdampak kepada dosen menjadi setia dengan pekerjaannya dan tidak ingin pindah dari pekerjaannya tersebut.

Penelitian ini memiliki beberapa keterbatasan diantaranya data yang digunakan dalam penelitian ini menggunakan instrumen kuesioner, yang mana hasil yang didapatkan dari responden bersifat persepsi, objek pada penelitian ini hanya terbatas pada dosen manajemen bisnis dan fakultas ekonomi saja, kurangnya sikap kepedulian dan keseriusan dari responden dalam menjawab, kuesioner yang digunakan kurang cocok diaplikasikan ke objek penelitian yaitu dosen.

Hasil penelitian mengungkapkan bahwa variabel gaya kepemimpinan mampu mempengaruhi kepuasan kerja. Kepuasan kerja akan meningkat apabila gaya kepemimpinan diperkuat. Implikasi kepada pihak perguruan tinggi untuk dapat menerapkan gaya kepemimpinan yang sesuai dengan kondisi dan juga dapat memberikan contoh perilaku kepemimpinan yang baik dan memotivasi bawahan sehingga bawahan merasa nyaman dalam bekerja maka akan menimbulkan kepuasan dalam diri dosen saat bekerja sehingga dapat meningkatkan kepuasan kerja.

Peningkatan kepuasan kerja akan meningkatkan komitmen organisasi. Hasil ini memberikan implikasi akan perlunya menciptakan kepuasan kerja bagi setiap karyawan. Peningkatan kepuasan kerja dapat dengan cara memberikan kesempatan promosi, memberikan gaji yang sesuai, memberikan pengawasan sehingga dengan begitu maka akan meningkatkan komitmen organisasi yang tinggi. Dosen akan menjadi setia dengan organisasinya dan tidak mengganti pekerjaan dengan yang lain.

Saran untuk penelitian kedepan yaitu sampel dapat dikembangkan meliputi dosen dan civitas perguruan tinggi, dapat menambahkan variabel lain yang masih erat 
hubungannya, misalnya turnover, kinerja kerja, ataupun dengan variabel lainnya, sampel dapat diganti dengan sektor lainnya seperti sektor perbankan, manufaktur ataupun sektor lainnya.

\section{PUSTAKA ACUAN}

Allen, N. J., \& Meyer, J. P. 1990. The Measurement and Antecedents of Affective, Continuance and Normative Commitment. Journal of Occupational Psychology, 63, I18.

Arzi, S., \& Farahbod, L. 2014. The Impact of Leadership Style on Job Satisfaction : A Study of Iranian Hotels. Interdisciplinary Journal Of Contemporary Research In Business, 6 (3), $|7|-\mid 86$.

Avolio, B. J., \& Bass, B. M. 2004. Multifactor Leadeship Questionnaire. Manual and sampler set. (3rd ed). Redwood City, CA: Mind Garden.

Azeem, S. M. 20I0. Job Satisfaction and Organizational Commitment among Employees in the Sultanate of Oman. Psychology, I, 295-299.

Baihaqi, M. F. 2010. Pengaruh Gaya Kepemimpinan terhadap Kepuasan Kerja dan Kinerja Dengan Komitmen Organisasi sebagai Variabel Intervening (Studi Pada PT. Yudhistira Ghalia Indonesia Area Yogyakarta).

Bass, B. M. 1990. From Transactional to Transformational Leadership: Learning to Share the Vision. Organizational Dynamics, 18 (3), 19-31.

Bass, B. M., \& Avolio, B. J. 1990. The Implications of Transactional and Transformational leadership for Individual, Team and Organizational Development. Research in Organizational Change and Development, 4, 231-272.

Choi Sang Long, W. M. 20I4. The Impact of Transformational Leadership Style on Job Satisfaction. World Applied Sciences Journal, 29 (I), II7-I 24.

Dewi, K. S. 2013. Pengaruh Gaya Kepemimpinan Transformasional terhadap Kepuasan Kerja Karyawan dan Komitmen Organisasi pada PT.KPM. Jurnal Manajemen, Strategi Bisnis, dan Kewirausahaan, 7 (2), II6-I25.

Ghozali, I. 20II. Aplikasi Analisis Multivariate dengan Program IBM SPSS 20. Semarang: Badan Penerbit Universitas Diponegoro.

Hartono, P. D. 2015. Metodologi Penelitian Bisnis: Salah Kaprah dan PengalamanPengalaman Edisi Keenam. Yogyakarta: BPFE UGM. 
Hasibuan, M. 2007. Manajemen Sumber Daya Manusia. Jakarta: Bumi Aksara.

Hsiao, J. M., \& Chen, Y. C. 20I2. Antecedents and consequences of job satisfaction: A case of automobile component manufacturer in Taiwan. Journal of Organizational Innovation, 5 (2), 164-178.

Judge, T. A., \& Locke, E. 1993. Effect of Dysfunctional Thought Processes on Subjective Well-Being and Job Satisfaction. Journal of Applied Psychology, 78 (3), 475490.

Kartono. 2003. Pemimpin dan Kepemimpinan. Jakarta: PT. Raja Grafindo.

Kemenristek dan Dikti. Pangkalan Data Pendidikan Tinggi Kementerian Riset, Teknologi dan Pendidikan Tinggi. Retrieved January 31, 2016, from forlab.dikti.go.id

Kreitner, R., \& Kinicki, A. 2003. Perilaku Organisasi Edisi Pertama. Jakarta: Salemba Empat.

Kurniawan, M. L. 20I5. Pengaruh Kepemimpinan Transformasional terhadap Komitmen Organisasi yang dimediasi Kepuasan Kerja Karyawan pada Bagian Produksi PT. Kurnia Bumi Pertiwi.

Long, C. S., Thean, L. Y., \& Kowang, T. O. 2013. The Trasformational Leadership: A Possible TQM Solution to Increase Job Satisfaction? Life Science Journal, 10 (4), I4741484.

Luthans, F. 2006. Perilaku Organisasi Edisi I0. Yogyakarta: Andi.

Malik, P. M., Nawab, D. S., Naeem, B., \& Danish, R. Q. 20I0. Job Satisfaction and Organizational Commitmen of University Teachers in Public Sector of Pakistan. International Journal of Business and Management, 5 (6), 17-26.

Mathis, R. L., \& Jackson. 20II. Human Resource Management. Jakarta: Salemba Empat.

Mohammad, M. S. 2012. Transformational Leadership and Employees' Job Satisfaction and Commitment: A Structural Equation Investigation. Journal of American Science, 8 (7), II-19.

Mohammed, F., \& Eleswed, M. 2013. Job Satisfaction and Organizational Commitment: A Correlational Study in Bahrain. International Journal of Business, Humanities and Technology, 3 (5), 43-53. 
Mowday, R. T., Porter, L. W., \& Steers, R. M. 1982. Employee Organization Lingkages: The Psychology of Commitment, Absenteeism and Turnover. London: Academic Press Inc.

Obuobisa, E., \& Obuobisa, T. 2015. Leadership and Employee Satisfaction in the Ghanaian Banking Sector. European Journal of Business and Management, 7 (8), 109-119.

Omidifar, R. 2013. Leadership Style, Organizational Commitment and Job Satisfaction: A Case Study on High School Principals in Tehran, Iran. American Journal of Humanities and Social Sciences, I (4), 263-267.

Puspitawati, N. M., \& Riana, I. G. 20I4. Pengaruh Kepuasan Kerja terhadap Komitmen Organisasional dan Kualitas Layanan. Jurnal Manajemen Strategi Bisnis dan Kewirausahaan, 8 (I), 68-80.

Rivai, V. 2003. Kepemimpinan dan Perilaku Organisasi. Jakarta: Raja Grafindo.

Robbins, S. P. 2008. Perilaku Organisasi Buku 2, Edisi 12. Jakarta : Salemba Empat.

Robbins, S. P., \& Judge, T. A. 2008. Perilaku Organisasi Buku I, Edisi I2. Jakarta: Salemba Empat.

Setiawan, B. D. 20II. Pengaruh Gaya Kepemimpinan Transaksional dan Transformational terhadap Kepuasan Kerja Karyawan pada Proyek Konstruksi.

Soureh Arzi, L. F. 2014. The Impact of Leadership Style on Job Satisfaction: A study of Iranian Hotels. Interdisciplinary Journal Of Contemporary Research In Business, 6 (3), |7|-|86.

Spector, P. E. 1997. Job satisfaction: Application, Assessment, Causes, and Cpnsequences. Thousand Oaks, CA: Sage.

Sreers, R. M., \& Lyman, W. P. 199I. Motivation and Work Behavior. Fifth Edition. Mc. Graw-Hill Edition.

Steers, R. M., \& Porter, L. W. 1983. Motivation and work behavior. Edisi 3. United States: McGraw-Hilll Book Company.

Sugiyono. 2008. Metode Penelitian Administrasi. Bandung: CV. ALFABETA. 
Tanzil Lu, E. L. 2013. Relevansi Geder terhadap Leadership Style dan Penerapan Result Control di Fakultas Bisnis Program Studi S-I Universitas "X". Jurnal Ilmiah Mahasiswa Universitas Surabaya, 2 (I).

Tondok, M. S., \& Andarika, R. 2004. The Correlation Between Transactional Transformational Leadership Style Perception and Employees' Job Satisfaction. Jurnal PSYCHE, I (I), 35-49. 